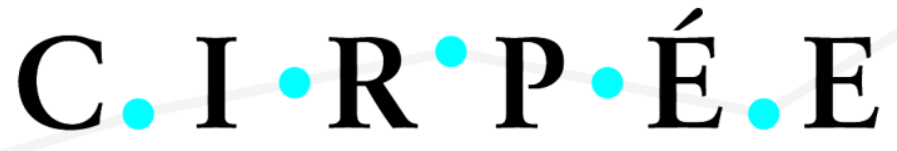

Centre Interuniversitaire sur le Risque, les Politiques Économiques et l'Emploi

Cahier de recherche/Working Paper 11-41

\section{A Structural Balance Sheet Model of Sovereign Credit Risk}

\author{
Pascal François \\ Georges Hübner \\ Jean-Roch Sibille
}

Décembre/December 2011

\footnotetext{
François: Associate Professor of Finance, HEC Montréal and CIRPÉE Research Fellow. Postal address: HEC Montréal, Department of Finance, 3000 Cote-Ste-Catherine, Montreal, Canada H3T 2A7

pascal.francois@hec.ca

Hübner: The Deloitte Professor of Financial Management, HEC Management School - University of Liège; Associate Professor of Finance, Faculty of Economics and Business Administration, Maastricht University; Chief Scientific Officer, Gambit Financial Solutions. Postal address: HEC Management School - University of Liège, 14 rue Louvrex, Bâtiment 1, B-4000 Liège, Belgium

g.hubner@ulg.ac.be

Sibille: Senior Consultant Riskdynamics. Postal address: Riskdynamics, 47-48 Boulevard du Régent, B-1000 Brussels, Belgium

JSibille@ riskdynamics.eu

We thank Alexandre Jeanneret for helpful discussions. Part of this research was completed while Jean-Roch Sibille was a Fellow of the Belgian Intercollegiate Center for Management Science (ICM). Pascal François acknowledges the financial support of SSHRC. Georges Hübner acknowledges the financial support of Deloitte Luxembourg. The usual disclaimer applies.
} 


\begin{abstract}
:
This article studies sovereign credit spreads using a contingent claims model and a balance sheet representation of the sovereign economy. Analytical formulae for domestic and external debt values as well as for the financial guarantee are derived in a framework where recovery rate is endogenously determined as the solution of a strategic bargaining game. The approach allows to relate sovereign credit spreads to observable macroeconomic factors, and in particular accounts for contagion effects through the corporate and banking sectors. Pricing performance as well as predictions about credit spread determinants are successfully tested on the Brazilian economy.
\end{abstract}

Keywords: Sovereign Credit Spread, Balance Sheet, Recovery Rate, Contingent Claims Analysis, Contagion Effects

JEL Classification: G13 


\section{Introduction}

In situations of financial turmoil, the assessment of sovereign credit risk plays an important role. It is a key challenge for countries to develop comprehensive models that are able to better understand and help prevent financial crisis. In order to provide a reasonable picture of a national economy, these models must reflect not only the dynamics of the public sector, but also the evolution of the private sector. In particular, the financial function filled by the banking system enables the sovereign government to interact with companies and households, but also with foreign lenders.

In this paper, we propose an inter-sectorial sovereign model of default risk that takes into account these interactions between the public, private, and banking sectors. Our modeling framework belongs to the stream of "structural-form models" because they analyze directly the evolution of underlying structural variables to determine the time, the probability or the distance to default. In this article, we adapt this approach to the credit risk of a sovereign economy, and identify specific parameters which can lead to a default by a sovereign borrower. For this purpose, we follow the approach of Gapen et al. (2005), and Gray, Merton and Bodie (2007, 2008). These authors view the economy as interconnected sectors represented by portfolios of assets, liabilities, and guarantees. This "balance sheet"

approach has the benefit of a wider perception of the sovereign default mechanism and therefore enriches the set of determinants on sovereign credit spreads.

One of our major contributions is to implement the balance sheet approach of the sovereign economy by use of the contingent claims analysis (CCA). The CCA was originally applied to assess the default probability of corporate entities. However, major differences exist between a country and a corporate default. For instance, if a firm can go bankrupt and literally cease to exist, such is not the case for a sovereign. Sovereign government can decide, for any value of national corporate assets, whether it has the incentive to default entirely, partially, or not at all on its foreign debt. To capture the full extent of this issue, we develop a Rubinstein (1982) type of strategic game played between the country and foreign debtholders. An endogenous recovery rate is obtained from the equilibrium of this 
game.

Building on the works by Gapen et al. (2005), Gray, Merton and Bodie (2007, 2008), we consider that the sovereign economy can be divided into three sectors: Corporate (including households), banking and public (government plus monetary authorities). In this setup, a sovereign crisis can have three possible origins. All three scenarios have in common that they ultimately put a stress on public liabilities, mainly on the financial guarantee, thereby triggering sovereign default.

1. Shocks on the corporate sector. A decrease in the value of corporate assets reduces the wealth of banks who have claims on them. This, in turn, might increase the value of the financial guarantee, putting the sovereign in a more difficult financial situation. A similar effect can result from a shock in corporate leverage. Underleveraged corporations induce a loss in profitability for lending banks. This, again, might require the contribution of the financial guarantee.

2. Shock on the banking sector. Following a major financial distress like a bank run or a systemic default, the value of deposits decreases, which increases the value of the financial guarantee (put on deposits). Another stress can stem from domestic debt to the extent that it is held for the most part by banks.

3. Shock on the public sector. In the case of a cut in fiscal revenues, a distress in the pension plan or a loss in foreign reserves, the sovereign can be hit directly. Note that fiscal revenues are intimately related to the size of corporate assets (including households).

After calibrating the model to a plausible representative sovereign economy, we derive testable implications regarding the determinants of sovereign credit spreads. In particular, we emphasize the contagion effect from the corporate sector on the cost of external financing. This contagion effect can be direct (through a shock on corporate assets) or indirect (through a change in corporate leverage). As far as the banking sector is concerned, we measure the contagion effect on sovereign credit spreads via changes in deposits. The model 
also explicitly values the financial guarantee which acts as a buffer between the banking and the public sectors.

Our approach is then empirically tested on the Brazilian economy. The model-implied credit spreads track the observed data reasonably well. In addition, most of the model predictions about the determinants of sovereign credit spreads (including contagion effects) are validated by a regression analysis.

Our paper stands at the cornerstone of two strands of literature. On the one hand, early CCA models have been applied to analyze sovereign credit risk. Kulatilaka and Marcus (1987) model the timing of sovereign strategic default as a first-hitting time problem using sovereign GDP as state variable. They do not examine the possibility of renegotiating debt terms upon default. The model by Cohen (1993) examines the value of a debt write-off, using the sovereign capacity to pay (expressed as a fraction of GDP) as the state variable. Hayri (2000) and Gibson and Sundaresan (2000) value sovereign debt in a contingent claims model where the defaulting sovereign is exposed to sanctions. These models show that there exists a value of waiting to default, which may explain the evidence of many sovereigns being deeply on the "wrong" side of the debt Laffer curve. The contingent claims model in Jeanneret (2011) uses the sovereign stock market index to analyze credit spreads at the daily frequency. All of these CCA models view default as a first-hitting time problem and therefore can only account for one sovereign default. In our setup, we allow for multiple sovereign defaults every time the state variable falls below the endogenous default threshold. This more realistic modeling approach is capable of generating higher credit spreads, since creditors anticipate their exposure to repeated defaults. On the other hand, more recent macroeconomic contributions model a small open economy to relate sovereign income, consumption and risk aversion to credit spreads. These works include Arellano (2008) and Yue (2010).

This paper is divided into five sections. In section 2, we present a comprehensive balance sheet representation of the sovereign economy. We apply the contingent claims analysis to value the components that connect the various accounts of the balance sheet, 
including corporate, domestic and external debts, as well as the financial guarantee. We also model the renegotiation process of sovereign default as a game between the sovereign and foreign debtholders. In the third section, we conduct a numerical analysis of the model to investigate the determinants of sovereign credit spreads. In section 4 , the model is empirically tested on the Brazilian economy. Section 5 concludes. Technical derivations are gathered in the appendix.

\section{The sovereign economy with contagion effects}

This section proposes an intuitive view of an economy in a balance sheet framework. After developing the different elements, we apply the CCA to relate the whole economy to a single stochastic variable, namely the corporate assets.

Figure 1 provides a balance sheet representation of the sovereign economy.

\section{Insert Figure 1 here}

Throughout we use the term "corporate" to designate the industry sector as a whole. The corporate sector therefore accounts for the country's real activity. The contingent claims model developed in the next section will use industrial production flow as the state variable. When the time comes for model calibration, we will typically use GDP statistics to proxy for the dynamics of the sovereign industrial production.

For simplicity, the banking sector accounts for the country's commercial banking activity. Also, we assume that only the public sector has access to world financial markets (see e.g. Cohen, 1991).

Note that the financial guarantee is included in sovereign equity. This is equivalent to assuming that, in case banks are in financial distress, the sovereign will dig into her pockets to trigger the financial guarantee and keep the banking system afloat. ${ }^{1}$ Prior

\footnotetext{
${ }^{1}$ In particular, the sovereign could increase the fiscal pressure or use her monetary prerogative, which would both increase public assets. Adding an endogenous fiscal and/or monetary policy is a challenging macroeconomic extension of the present work.
} 
evidence on sovereign debt crises suggests that emerging countries in financial difficulty with their external creditors preserve the stability of their banking system.

In our model, we focus on a shock coming from the corporate assets. We could extend the model to consider the public assets or the bank deposits as additional variables. However, to obtain a clear prospective and to simplify the interconnections inside the balance sheet, we work only with one stochastic variable, and keep the other inputs (bank deposits and public assets) fixed.

\subsection{Contingent claims analysis}

\subsubsection{Notations and assumptions}

The following assumptions are needed in order to use the CCA to depict the dynamics of the key balance sheet components.

Assumption 1: Public domestic debt, as well as foreign debt, are perpetuities with continuous debt service.

We denote by $s_{d}$ and $s_{f}$ the continuous debt service offered by domestic and foreign debts, respectively.

Assumption 2: Domestic investors are exposed to an idiosyncratic source of risk that they cannot diversify away (see assumption 3 below). Foreign lenders, by contrast, have unrestricted access to international capital markets.

A similar assumption can be found in sovereign debt models such as Arellano (2008) or Yue (2010). A direct consequence is that the rate of time preference of domestic investors is higher than that of foreign investors (typically large international financial institutions). We denote by $r_{d}\left(r_{f}\right)$ the rate at which domestic (foreign) investors discount all future payoffs. Following assumption 2, we have that $r_{f}<r_{d}$.

Assumption 3: The value of sovereign industrial production flow, denoted by $V$, follows a geometric Brownian motion

$$
\frac{d V(t)}{V(t)}=\mu d t+\sigma d W(t)
$$


where $\mu$ is the drift rate, $\sigma$ is the standard deviation and $W$ represents a Wiener process.

Consequently, the value of the whole corporate sector is that of a perpetuity with initial flow $V$, growing at rate $\mu$ and discounted at rate $r_{d}$. That is, the whole corporate sector is worth

$$
\frac{V}{r_{d}-\mu}
$$

Assumption 4: If the sovereign repudiates her debt, foreign lenders impose sanctions such that the drift of sovereign industrial production drops to $\mu_{2}<\mu$.

Evidence on drops in sovereign GDP growth rate after default is found in Sturzenegger and Zettelmeyer (2008) and Borensztein and Panizza (2008).

Assumption 5: The corporate sector is leveraged and corporate debt is a perpetuity with continuous coupon $s_{c}$. Let us denote by $V_{b}$ the critical threshold at which the corporate sector defaults on its debt. At this point, the country's assets are reorganized under the supervision of domestic lenders (and we assume corporate equityholders leave with nothing). ${ }^{2}$

Assumption 6: The domestic banking sector is responsible for all corporate loans. Additionally, these loans are exclusively financed by deposits (pure commercial banking). We further assume that deposits generate a continuous flow $\delta$ accruing to bank account owners.

Bank assets consist of all corporate loans, the public domestic debt and the public financial guarantee. As proposed by Ronn and Verma (1986), we see the financial guarantee as a put option on bank assets ensuring that the government intervenes if the bank assets fall below the value of the deposits. This provision guarantees that the savings from the corporate sector are safe.

Assumption 7: The sovereign will enter into renegotiations with domestic and foreign creditors every time the value of industrial production flow falls below a critical level $R$. Domestic and foreign debts are treated equally during renegotiations, that is, they exhibit the same priority level and the same negotiated recovery rate. Specifically, during debt

\footnotetext{
${ }^{2}$ For simplicity, we assume that reorganization of the whole corporate sector may occur only once over the infinite horizon. As a consequence, the timing of corporate reorganization is modeled as a first-hitting time. We leave the case for repeated failures of the corporate sector as an extension of the model.
} 
renegotiations, debt service is reduced to $\alpha s_{d}$ for domestic debt and to $\alpha s_{f}$ for foreign debt with $0<\alpha<1$.

Given there is no clear evidence in the literature of a systematically higher domestic recovery rate compared to the foreign recovery rate (or the opposite) ${ }^{3}$ we rely on Assumption 7 to keep the model tractable without giving away its potential insights.

\subsubsection{Valuation}

The critical threshold for renegotiation $(R)$ will be first regarded as exogenous, but it will later be made endogenous. Under previous assumptions, the values of domestic debt $\left(D_{d}\right)$ and foreign debt $\left(D_{f}\right)$ are given by (see Appendix for a proof)

$$
D_{k}(V, R, \alpha)= \begin{cases}\frac{s_{k}}{r_{k}}-\frac{(1-\alpha) s_{k}}{\Psi_{k}^{+}}\left(\frac{R}{V}\right)^{\frac{\Phi_{k}^{+}}{\sigma}} & \text { for } V>R \\ \frac{\alpha s_{k}}{r_{k}}+\frac{(1-\alpha) s_{k}}{\Psi_{k}^{-}}\left(\frac{R}{V}\right)^{-\frac{\Phi_{k}^{-}}{\sigma}} & \text { for } V \leq R\end{cases}
$$

for $k=d, f$ and with

$$
\begin{aligned}
\Phi_{k}^{+/-} & =\sqrt{2 r_{k}+\lambda^{2}} \pm \lambda \\
\Psi_{k}^{+/-} & =2 r_{k}+\lambda^{2} \pm \lambda \sqrt{2 r_{k}+\lambda^{2}} \\
\lambda & =\mu / \sigma-\sigma / 2 .
\end{aligned}
$$

For corporate debt, we obtain

$$
D_{c}\left(V, V_{b}\right)=\frac{s_{c}}{r_{d}}-\left(\frac{s_{c}}{r_{d}}-\frac{V_{b}}{r_{d}-\mu}\right)\left(\frac{V_{b}}{V}\right)^{\frac{\Phi_{d}^{+}}{\sigma}},
$$

and the value of corporate equity is therefore

$$
S_{c}\left(V, V_{b}\right)=\frac{V}{r_{d}-\mu}-D_{c}\left(V, V_{b}\right)
$$

\footnotetext{
${ }^{3}$ Gelpern and Setser (2004) provide evidence of preference given to domestic lenders as in the case of Russia in 1998 as well as Turkey in 2001. However, they conclude that domestic and foreign lenders were treated equally after the Uruguayan default in 2003. Sturzenegger and Zettelmeyer (2008) cannot reject the assumption of equal treatment between domestic and foreign lenders on a sample of 10 debt restructurings in 6 countries.
} 
Optimal default threshold for corporate equityholders is given by the smooth pasting condition

$$
\left.\frac{\partial\left(S_{c}(V)\right)}{\partial V}\right|_{V=V_{b}}=0 .
$$

Which yields

$$
V_{b}^{*}=\frac{s_{c}\left(r_{d}-\mu\right)}{r_{d}} \frac{\Phi_{d}^{+}}{\sigma+\Phi_{d}^{+}} .
$$

For the banking sector to be viable, it must be that the cash flow received from borrowers exceeds the one due to depositors. That is,

$$
s_{c}+s_{d}>\delta
$$

However, in times of debt renegotiations, the financial health of the banking sector is jeopardized if

$$
s_{c}+\alpha s_{d}<\delta .
$$

This is when the financial guarantee intervenes. It makes up for the difference between the cash flow due to depositors and the cash flow actually received by banks. Hence, the financial guarantee pays the coupon $\delta-s_{c}-\alpha s_{d}$ (if positive) every time sovereign debt is being renegotiated. The value of the financial guarantee is therefore given by (see Appendix)

$$
G(V, R, \alpha)= \begin{cases}\frac{\max \left(0, \delta-s_{c}-\alpha s_{d}\right)}{\Psi_{d}^{+}}\left(\frac{R}{V}\right)^{\frac{\Phi_{d}^{+}}{\sigma}} & \text { for } V>R \\ \frac{\max \left(0, \delta-s_{c}-\alpha s_{d}\right)}{r_{d}}-\frac{\max \left(0, \delta-s_{c}-\alpha s_{d}\right)}{\Psi_{d}^{-}}\left(\frac{R}{V}\right)^{-\frac{\Phi_{d}^{-}}{\sigma}} & \text { for } V \leq R\end{cases}
$$

From the banking balance sheet equality, banking equity is worth

$$
S_{b}(V, R, \alpha)=D_{c}\left(V, V_{b}^{*}\right)+D_{d}(V, R, \alpha)+G(V, R, \alpha)-\frac{\delta}{r_{d}} .
$$

Figure 2 presents the balance sheet of the sovereign economy using the contingent claims we have introduced and valued.

Insert Figure 2 here 


\subsection{The debt renegotiation game}

Every time sovereign industrial production hits the renegotiation threshold $R$, we assume that a bargaining game takes place between the sovereign state and foreign lenders. Following Hayri (2000), we consider a Rubinstein (1982) type of game where the two parties take turns to make offers. In this type of game, Rubinstein (1982) shows that the unique subgame perfect equilibrium is an immediate agreement in which the renegotiation surplus is shared according to the difference of rate of time preference. That is, foreign creditors get a fraction

$$
\frac{r_{d}-\mu}{r_{d}-\mu+r_{f}-\mu}
$$

of the renegotiation surplus which is the avoidance of economic sanctions, i.e.

$$
\frac{R}{r_{d}-\mu}-\frac{R}{r_{d}-\mu_{2}}
$$

Consequently, the equilibrium recovery rate is $\alpha^{*}$ such that what foreign creditors recover equals the fraction of the renegotiation surplus granted to them. This recovery is equivalent to a payment stream of $\alpha^{*} s_{f}$ every time $V$ is below $R$ valued at the renegotiation point (when $V=R$ ). From earlier calculations, we therefore obtain that $\alpha^{*}$ is such that

$$
\frac{\alpha^{*} s_{f}}{\Psi_{f}^{+}}=\frac{r_{d}-\mu}{r_{d}-\mu+r_{f}-\mu}\left(\frac{R}{r_{d}-\mu}-\frac{R}{r_{d}-\mu_{2}}\right),
$$

which yields

$$
\alpha^{*}=\frac{R}{s_{f}} \frac{\Psi_{f}^{+}}{r_{d}-\mu+r_{f}-\mu} \frac{\mu-\mu_{2}}{r_{d}-\mu_{2}} .
$$

To determine the optimal renegotiation threshold, we assume that the sovereign government aims to maximize the value of the whole nation's net wealth, that is the sum of corporate, banking and sovereign equities. ${ }^{4}$ From our balance sheet analysis in Figure 2, the sovereign therefore aims at maximizing the following

$$
S_{c}(V)+S_{b}(V, R, \alpha)+P-D_{d}(V, R, \alpha)-D_{f}(V, R, \alpha) .
$$

\footnotetext{
${ }^{4}$ Alternate specifications of the model could consider putting weights on the three types of equity, reflecting the sovereign government's political priorities.
} 
Applying the smooth-pasting condition

$$
\left.\frac{\partial\left(S_{c}(V)+S_{b}(V, R, \alpha)+P-D_{d}(V, R, \alpha)-D_{f}(V, R, \alpha)\right)}{\partial V}\right|_{V=R}=0,
$$

yields

$$
\begin{aligned}
R^{*}= & \frac{r_{d}-\mu}{\sigma}\left(\sqrt{2 r_{d}+\lambda^{2}}+\lambda\right) \frac{\max \left(0, \delta-s_{c}-\alpha^{*} s_{d}\right)}{\left(2 r_{d}+\lambda^{2}+\lambda \sqrt{2 r_{d}+\lambda^{2}}\right)} \\
& +\frac{r_{d}-\mu}{\sigma}\left(\sqrt{2 r_{f}+\lambda^{2}}+\lambda\right) \frac{\left(1-\alpha^{*}\right) s_{f}}{2 r_{f}+\lambda^{2}+\lambda \sqrt{2 r_{f}+\lambda^{2}}} .
\end{aligned}
$$

If $\delta-s_{c}-\alpha s_{d} \leq 0$, i.e. $\alpha \geq \frac{\delta-s_{c}}{s_{d}}$ then the expression for sovereign default threshold simplifies into

$$
R^{*}=\frac{r_{d}-\mu}{\sigma}\left(\sqrt{2 r_{f}+\lambda^{2}}+\lambda\right) \frac{\left(1-\alpha^{*}\right) s_{f}}{2 r_{f}+\lambda^{2}+\lambda \sqrt{2 r_{f}+\lambda^{2}}} .
$$

Combining this result with equation (4) yields

$$
R^{*}=\frac{\Phi^{+} s_{f}}{\Psi^{+}} /\left(\frac{\sigma}{r_{d}-\mu}+\frac{\Phi^{+}\left(\mu-\mu_{2}\right)}{\left(r_{d}-\mu+r_{f}-\mu\right)\left(r_{d}-\mu_{2}\right)}\right)
$$

and

$$
\alpha^{*}=\frac{\Phi^{+}\left(\mu-\mu_{2}\right)\left(r_{d}-\mu\right)}{\sigma\left(r_{d}-\mu+r_{f}-\mu\right)\left(r_{d}-\mu_{2}\right)+\Phi^{+}\left(\mu-\mu_{2}\right)\left(r_{d}-\mu\right)} .
$$

Note that in this case, the financial guarantee is not activated $\left(\delta-s_{c}-\alpha s_{d} \leq 0\right)$. As a result, there is no stress on the banking sector and therefore, the sovereign decision to default $\left(R^{*}\right)$ only depends on external indebtedness $\left(s_{f}\right)$. Furthermore, since the sovereign default threshold is linear in $s_{f}$, the optimal recovery rate is constant across all external debt levels.

If $\delta-s_{c}-\alpha s_{d}>0$, i.e. $\alpha<\frac{\delta-s_{c}}{s_{d}}$ then the expression for sovereign default threshold is now

$$
\begin{aligned}
R^{*}= & \frac{r_{d}-\mu}{\sigma}\left(\sqrt{2 r_{d}+\lambda^{2}}+\lambda\right) \frac{\delta-s_{c}-\alpha^{*} s_{d}}{\left(2 r_{d}+\lambda^{2}+\lambda \sqrt{2 r_{d}+\lambda^{2}}\right)} \\
& +\frac{r_{d}-\mu}{\sigma}\left(\sqrt{2 r_{f}+\lambda^{2}}+\lambda\right) \frac{\left(1-\alpha^{*}\right) s_{f}}{2 r_{f}+\lambda^{2}+\lambda \sqrt{2 r_{f}+\lambda^{2}}}
\end{aligned}
$$


Rearranging and plugging the expression for $\alpha^{*}$ from equation (4) yields

$$
R^{*}=\frac{r_{d}-\mu}{\sigma}\left(\frac{\Phi_{d}\left(\delta-s_{c}\right)}{\Psi_{d}}+\frac{\Phi_{f} s_{f}}{\Psi_{f}}\right) /\left(1+\frac{r_{d}-\mu}{\sigma} \frac{\mu-\mu_{2}}{r_{d}-\mu_{2}} \frac{\Phi_{d} \Psi_{f} s_{d}+\Phi_{f} \Psi_{d} s_{f}}{\Psi_{d}\left(r_{d}-\mu+r_{f}-\mu\right) s_{f}}\right),
$$

and

$$
\begin{aligned}
\alpha^{*}= & \left(\frac{\Psi_{f}}{r_{d}-\mu+r_{f}-\mu}\right)\left(\frac{\mu-\mu_{2}}{r_{d}-\mu_{2}}\right) \frac{r_{d}-\mu}{\sigma}\left(\frac{\Phi_{d}\left(\delta-s_{c}\right)}{\Psi_{d} s_{f}}+\frac{\Phi_{f}}{\Psi_{f}}\right) \\
& /\left(1+\frac{r_{d}-\mu}{\sigma} \frac{\mu-\mu_{2}}{r_{d}-\mu_{2}} \frac{\Phi_{d} \Psi_{f} s_{d}+\Phi_{f} \Psi_{d} s_{f}}{\Psi_{d}\left(r_{d}-\mu+r_{f}-\mu\right) s_{f}}\right) .
\end{aligned}
$$

In this case, the financial guarantee has a strict positive value and the banking sector is under stress. As a result, a contagion effect makes the sovereign decision to default dependent on external, domestic and corporate indebtedness. Since the relation between the default threshold and external indebtedness is not linear, the optimal recovery rate will depend on $s_{f}$ in this case.

\section{Numerical analysis}

\subsection{Model calibration}

The model relies on nine country-specific parameters plus the world interest rate $\left(r_{f}\right)$. All parameters are proxied with variables from the World Development Indicators - an extensive dataset administrated by the World Bank. These annual proxies are expressed as a percentage of GDP, which allows us to apply the model with a state variable normalized to $V=100 .^{5}$ Table 1 lists our selected variables and the parameter they account for.

Insert Table 1 here

\footnotetext{
${ }^{5}$ Note that, as far as model development is concerned, the state variable has been assimilated to the sovereign industrial production flow. But calibration to the data requires scaling the model to sovereign GDP. Hence, we numerically investigate shocks on sovereign GDP, but their effects are qualitatively equivalent to shocks on industrial production flow.
} 
Average GDP growth is a proxy for parameter $\mu$. Parameter $s_{f}$ is proxied by external debt stock which is the sum of public, publicly-guaranteed, and private non-guaranteed long-term debt, use of IMF credit, and short-term debt. We use the domestic credit provided by the banking sector to account for $s_{d}$. We follow a similar procedure for parameter $s_{c}$ using the domestic credit to the private sector. Deposits are proxied by the variable "Broad Money," which mainly consists of currency outside banks, demand deposits other than those of the central government, the time, savings, and foreign currency deposits of resident sectors other than the central government.

The country-specific estimation procedure for volatility involves time series of daily sovereign credit spreads, and is detailed in the empirical analysis section. It is based on the iterative procedure developed by KMV Corporation (2002) and Vassalou and Xing (2004) among others.

Finally, empirical work from Sturzenegger and Zettelmeyer (2008) and Borensztein and Panizza (2008) documents that the sovereign GDP growth rate typically falls after a default. Sturzenegger and Zettelmeyer (2008) report a drop of between 0.5 and 2 percentage points. Borensztein and Panizza (2008) find an average drop of 1.2 percentage points. Accordingly, we simply set

$$
\mu_{2}=\mu-0.01
$$

Note that the value for the world interest rate is obtained as the average 3-month U.S. Treasury Bill rate (obtained from the Federal Reserve of St-Louis).

Numerical implementation of the model is illustrated with data from a selection of major participants in the sovereign debt market over the 1995-2009 period. ${ }^{6}$ Table 2 reports the average values of the proxies for the model parameters. For the sole purpose of model simulation, the standard deviation of annual GDP log-returns will serve as a crude proxy for volatility. Although the selected sovereign countries display a growth rate and a volatility within a relatively narrow range, Table 2 shows great discrepancy in debt and

\footnotetext{
${ }^{6}$ Statistics for 2010 were not available at the time of data extraction.
} 
deposit levels. In this context, the base case scenario reflects a plausible calibration for a moderately indebted country.

Insert Table 2 here

In the base case indeed, we obtain that the distance-to-default (defined as $100 / R^{*}$ ) is around 1.25. Given that the state variable drift and volatility are $3 \%$ and $20 \%$ respectively, this implies that the sovereign has an approximately $24 \%$ chance of defaulting within a year. Endogenous recovery rate is $11 \%$. This figure is in the same magnitude as the endogenous recovery rates obtained by Jeanneret (2011) for sovereigns with high bargaining power (which is, arguably, the case for our selected countries). Across all types of sovereign defaulters however, recovery rates reported by Moody's (2009) are slightly higher (around $30 \%$ on average). Base case sovereign credit spread is around 120 basis points, reflecting the moderately safe situation of the sovereign.

\subsection{Determinants of sovereign credit spreads}

Figures 3 and 4 represent how model-implied sovereign credit spreads react to shocks in model inputs. In these simulations, the sovereign credit spread (cs) is defined as

$$
c s=\frac{s_{f}}{D_{f}\left(V, R^{*}, \alpha^{*}\right)}-r_{f} .
$$

A sovereign with a higher rate of time preference will apply a bigger discount on external debt, hence credit spread increases with $r_{d}$. The same effect applies to foreign creditors who should demand a higher risk premium as $r_{f}$ increases. At the same time, however, an increase in $r_{f}$ lowers the endogenous default threshold and raises the endogenous recovery rate. Overall, these two effects more than offset the discounting effect, hence credit spreads are mainly decreasing with $r_{f}$ (except for very small values) - which is a standard prediction in contingent claims models. Intuitively, sovereign credit spreads decrease with $\mu$ and increase with $\sigma$, since declining and more volatile industrial revenues make sovereign default more likely. Note that the recovery rate is a decreasing function of volatility (figure not reported), which is in line with the theoretical predictions of Jeanneret (2011). 
A small increase in low values of $s_{f}$ raises the credit spread in a linear fashion (see Figure 4). This is because the endogenous default threshold and recovery rate are mostly unaffected. However, as external debt becomes significant, the increase in credit spread is more than linear as the likelihood and severity of default are directly affected. Figure 4 shows the model is flexible enough to generate relatively high spreads (several hundreds of basis points) given a shock on external debt level. The adequacy of model-implied credit spreads with actual spreads will be examined more in depth in the empirical analysis section.

Figure 4 also illustrates some contagion effects captured by our contingent claims model. Most interesting is the effect stemming from the corporate sector in the sovereign economy. If it is under-leveraged, then bank assets are weakened and the financial guarantee has a strict positive value. This causes sovereign credit spreads to rise. Beyond a certain level of corporate debt (around 25\% of GDP in our base case), banks' lending activity covers the remuneration of deposits and the sovereign financial sector is sound - leaving sovereign credit spreads unaffected by additional corporate leverage. The bottom left graph of Figure 4 therefore sheds light on a cascade effect. If corporate activity is slowing down, the negative shock on GDP can be accentuated by a reduction in corporate debt service (because some companies cannot actually pay their debt) that weakens the financial health of the banking sector, activates the financial guarantee, and further increases sovereign credit spreads.

A similar contagion effect originating from the banking sector is depicted in the bottom right graph of Figure 4. If deposit flows increase to a certain level (around $35 \%$ of GDP in our base case), this will put sovereign banks under stress and activate the financial guarantee, which, in turn, makes external debt more risky.

Unfortunately, the model predicts no direct contagion effect from the domestic debt level (see the top right graph of Figure 4). This is because we have assumed that domestic debt is neutral in the sovereign decision to default. Capturing this additional source of contagion risk is an interesting avenue for extending this work. 


\section{Case study of the Brazilian economy}

In this section we gauge the model's ability to replicate realistic time series of sovereign credit spreads. We use Brazil as the reference country for our empirical illustration. Figure 5 shows the evolution of $s_{c}, s_{d}, s_{f}$ and $\delta$ for this country over the 1995-2009 period. Brazil has significantly increased its level of domestic debt throughout the sample period. Deposits have followed a similar pattern. The country experienced a momentary surge in its external indebtedness in the beginning of the 2000s. The corporate debt level has mirrored that of external debt.

\section{Insert Figure 5 here}

Brazilian credit spreads are proxied by the JP Morgan EMBI (Emerging Market Bond Index) Brazil spread available from Datastream. The model is challenged to replicate this time series at the monthly frequency. To this end, all annual data from the World Bank Indicators are converted into monthly data using linear interpolation.

\subsection{Volatility estimation}

To estimate the model's volatility, we follow the iterative procedure developed by KMV Corporation (2002) or Vassalou and Xing (2004) among others. In a first step, we compute the volatility $\widehat{\sigma}_{1}$ as the standard deviation of log-returns on observed credit spreads over one year. In step 2, the formula for the theoretical spread (equation (5)) is numerically inverted (using volatility $\widehat{\sigma}_{1}$ ) to retrieve the state variable value $(V)$ which allows to match the formula with the observed spread. These repeated inversions (over one year) yield a time series for $V$ (step 3). Computing the standard deviation of log-returns on $V$ yields a new estimate for volatility $\widehat{\sigma}_{2}$. We can now repeat steps 2 and 3 using $\widehat{\sigma}_{2}$ as the new volatility estimate. This will yield another volatility estimate $\widehat{\sigma}_{3}$, and so on and so forth. The procedure stops when two consecutive volatility estimates differ by less than a tolerance threshold (set at $10^{-6}$ in our case). Figure 6 shows the results for estimated volatility.

Insert Figure 6 here 
The iterative estimation procedure is applied once every year (from January to December), yielding a volatility estimate at the end of the year. Monthly volatility is then obtained by linear interpolation.

Brazil stands amongst the risky sovereign borrowers. In quiet times, volatility estimates reach a low of 30\%. In turbulent times however (most notably the sequels of the 1998 Russian crisis and the 1999-2002 Argentinian crisis), these estimates climb to $60 \%$ or even $80 \%$.

\subsection{Pricing performance}

Repeated application of equation (5) on a monthly basis generates model-implied sovereign credit spreads. In Figure 7, we compare these spreads with actual ones.

\section{Insert Figure 7 here}

Overall, the model does a reasonably good job in tracking the evolution of observed spreads. The most notable failure is the brutal spike in observed spreads which occurred during 2002 that the model fails to capture. Because the model is fed with smoothed annual data from the World Bank, its ability to adjust to short-lived episodes is limited. Arguably, the model could fit the data even closer if it were using higher frequency (i.e. more timely) inputs.

The mean error is slightly positive ( 62 basis points or $11 \%$ in relative terms), indicating that the model is apparently not biased towards under- or over-valuation. The root mean squared error (RMSE) is 241 basis points (37\% in relative terms), and is rather substantial, which, again, can be attributed to the low frequency of inputs.

\subsection{Regression analysis}

We assess the quality of model predictions regarding the determinants of sovereign credit spreads by use of regressions. The first four specifications test for the explanatory power of the model's outputs, namely the theoretical credit spreads, the default threshold and 
the recovery rate. Specifications 1 and 3 can be written as follows

$$
\begin{aligned}
& \ln \left(o b s \_c s_{t}\right)=a_{1}+b_{1} \ln \left(c s_{t}\right)+e_{1 t}, \\
& \ln \left(o b s \_c s_{t}\right)=a_{2}+b_{2} D T D_{t}+c_{2} \alpha_{t}^{*}+e_{2 t},
\end{aligned}
$$

where $o b s_{-} c s_{t}$ stands for the JP Morgan EMBI Brazil credit spread observed at month $t$, $c s_{t}$ is the model-implied credit spreads, $D T D_{t}$ is the endogenous distance-to-default (i.e. $\left.100 / R_{t}^{*}\right)$, and $\alpha_{t}^{*}$ is the endogenous recovery rate. Specifications 2 and 4 are the same regressions augmented with time-fixed effects (captured by annual dummies).

Next, we test for the explanatory power of credit spread determinants identified by the model. Thus, specification 5 is

$$
\ln \left(o b s_{-} c s_{t}\right)=a_{3}+B_{3} X_{t}+e_{3 t},
$$

with $X_{t}=\left\{r_{d}, r_{f}, \sigma, \mu, s_{f}, s_{d}, s_{c}, \delta\right\}$. Specification 6 includes time-fixed effects.

Table 3 reports the regression results.

Insert Table 3 here

We first note the relatively high explanatory power of the model-implied credit spreads. After controlling for time-fixed effects, the theoretical credit spread variations account for nearly $85 \%$ of actual credit spread variations. In comparison, the adjusted R-squares obtained in similar regressions by Hilscher and Nosbuch (2010), Jeanneret (2011), and Yue (2010) are $45 \%, 75 \%$ and $78 \%$, respectively.

As expected, the endogenous recovery rate has a significant negative impact on credit spreads, which should also be the case for the distance-to-default. Unfortunately, when time-fixed effects are included, the significant and positive coefficient comes at odds with model predictions. This anomaly may be explained by the relatively high correlation between the two regressors $(+0.579$ and significant at the $1 \%$ confidence level).

The predicted impacts of the sovereign discount rate $\left(r_{d}\right)$, world interest rate $\left(r_{f}\right)$, and volatility $(\sigma)$ on credit spreads are strongly supported by the regression analysis and are 
robust to time-fixed effects. The drift effect is also properly captured but is not robust to time-fixed effects.

The contagion effect via the corporate sector is validated only when time-fixed effects are accounted for. By contrast, the contagion effect via deposits is not detected in the Brazilian data. The regression analysis on this country also shows that the potential contagion effect via domestic debt $\left(s_{d}\right)$, which the model ignores, does not seem to matter much, as it is weakly detected (at the $10 \%$ confidence level) in the specification with timefixed effects, only. Yet, the positive and weakly significant coefficient for $s_{d}$ suggests that the sovereign may partly ground on domestic indebtedness her decision to default.

All in all, the regression analysis for Brazil provides a fairly strong support to the model as 9 out of 10 predicted relations are either fully (5) or partially (4) validated in the data.

\section{Conclusion}

By combining the contingent claims analysis and the balance sheet view of the sovereign economy, we have derived a pricing model for sovereign credit spreads that account for contagion effects throughout the economy. With endogenously determined recovery rates, the model-implied credit spreads can be related to observable macroeconomic quantities. To the best of our knowledge, some of these relations (and in particular contagion effects) have not been explicitly measured in the literature.

The model is successfully tested on the Brazilian economy. Admittedly, a more comprehensive assessment of the approach requires implementing the model on other countries, and this is left for future research.

Extensions of the model include adding domestic lenders (i.e. banks) into the renegotiation process. This would allow to explicitly account for an additional contagion effect emanating from the banking sector. Furthermore, the assumption of equal treatment between domestic and foreign lenders could be relaxed. But empirical evidence indicates that, in the absence of any systematic bias, a case-by-case approach should be adopted. 


\section{References}

[1] Arellano C. (2008), "Default Risk and Income Fluctuations in Emerging Economies," American Economic Review 98, pp. 690-712.

[2] Borensztein E. and U. Panizza (2008), "The Costs of Sovereign Default," IMF Working Paper, WP 08238.

[3] Cohen D. (1993), "A Valuation Formula for LDC Debt," Journal of International Economics 34, pp. 167-180.

[4] Cohen D. (1991), Private Lending to Sovereign States - A Theoretical Autopsy, MIT Press.

[5] Francois P. and E. Morellec (2008), "Closed-form Solutions to Stochastic Process Switching Problems," Journal of Mathematical Economics 44, pp. 1072-1083.

[6] Gapen M., D. Gray, C. H. Lim and Y. Xiao (2005), "Measuring and Analyzing Sovereign Risk with Contingent Claims," IMF Working Paper \#05/155.

[7] Gelpern A. and B. Setser (2004), "Domestic and External debt: The Doomed Quest for Equal Treatment," Georgetown Journal of International Law 35, pp. 795814.

[8] Gibson R. and S. Sundaresan (2000), "A Model of Sovereign Borrowing and Sovereign Yield Spreads," Working Paper HEC Lausanne and Columbia University.

[9] Gray D., R. C. Merton and Z. Bodie (2007), "Contingent Claims Approach to Measuring and Managing Sovereign Credit Risk," Journal of Investment Management 5, pp. 5-28.

[10] Gray D., R. C. Merton and Z. Bodie (2008), "New Framework for Measuring and Managing Macrofinancial Risk and Financial Stability," Harvard Business School Working Paper 09-015. 
[11] Hayri A. (2000), "Debt Relief," Journal of International Economics 52, pp. 137-152.

[12] Hilscher J. and Y. Nosbuch (2010), "Determinants of Sovereign Risk: Macroeconomic Fundamentals and the Pricing of Sovereign Debt," Review of Finance 14, pp. 235-262.

[13] Jeanneret A. (2011), "The Dynamics of Sovereign Credit Risk," EFA 2009 Bergen Meetings Paper. Available at SSRN: http://ssrn.com/abstract=1071665.

[14] Karatzas I. and S. Shreve (1991), Brownian Motion and Stochastic Calculus, Springer Verlag.

[15] KMV Corporation (2002), "Modeling Default Risk," Technical report.

[16] Kulatilaka N. and A. Marcus (1987), "A Model of Strategic Default of Sovereign Debt," Journal of Economic Dynamics and Control 11, pp. 483-498.

[17] Moody's (2009), "Sovereign default and recovery rates 1983-2008," Moody's global credit policy.

[18] Ronn E. and A. Verma (1986), "Pricing Risk-Adjusted Deposit Insurance: An Option Based Model," Journal of Finance 41, pp. 871-895.

[19] Rubinstein A. (1982), "Perfect Equilibrium in a Bargaining Model," Econometrica 50, pp. 97-109.

[20] Sturzenegger F. and J. Zettelmeyer (2008), "Haircuts: Estimating Investor Losses in Sovereign Debt Restructurings, 1998-2005," Journal of International Money and Finance 27, pp. 780-805.

[21] Vassalou M. and Y. Xing (2004), "Default Risk in Equity Returns," Journal of Finance 59, pp. 831-868.

[22] Yue V. (2010), "Sovereign Default and Debt Renegotiation," Journal of International Economics 80, pp. 176-187. 


\section{Appendix}

\section{Debt valuation}

We will detail the proof for the valuation of domestic debt. Foreign debt is valued along the same line of reasoning with $s_{d}$ replaced by $s_{f}$ and $r_{d}$ replaced by $r_{f}$. Domestic debtholders receive a payment $s_{d}$ every time sovereign industrial production $V$ is above $R$. Otherwise, they receive the reduced payment $\alpha s_{d}$. Consequently, the no-arbitrage value of domestic debt is given by

$$
D_{d}(V, R, \alpha)=E\left(s_{d} \int_{0}^{+\infty} e^{-r_{d} t} 1_{V_{t}>R} d t+\alpha s_{d} \int_{0}^{+\infty} e^{-r_{d} t} 1_{V_{t} \leq R} d t\right),
$$

where $1_{\omega}$ denotes the indicator function for the event $\omega$. Using the strong solution for the geometric Brownian motion, the latter can be rewritten as

$D_{d}(V, R, \alpha)=E\left(s_{d} \int_{0}^{+\infty} e^{-r_{d} t} 1_{W_{t}+\left(\frac{\mu}{\sigma}-\frac{\sigma}{2}\right) t>\frac{1}{\sigma} \ln \frac{R}{V}} d t+\alpha s_{d} \int_{0}^{+\infty} e^{-r_{d} t} 1_{W_{t}+\left(\frac{\mu}{\sigma}-\frac{\sigma}{2}\right) t \leq \frac{1}{\sigma} \ln \frac{R}{V}} d t\right)$.

Consider the change of probability measure using the following Radon-Nykodym derivative

$$
\exp \left[-\left(\frac{\mu}{\sigma}-\frac{\sigma}{2}\right) W_{t}-\frac{1}{2}\left(\frac{\mu}{\sigma}-\frac{\sigma}{2}\right)^{2} t\right] \text {. }
$$

Under the new measure, we know from Girsanov theorem that $\widetilde{W}_{t}:=W_{t}+\left(\frac{\mu}{\sigma}-\frac{\sigma}{2}\right) t$ is a Brownian motion. The domestic debt value is now given by

$D_{d}(V, R, \alpha)=\widetilde{E}\left(s_{d} \int_{0}^{+\infty} e^{-r_{d} t} e^{\lambda \widetilde{W}_{t}} e^{-\frac{\lambda^{2}}{2} t} 1_{\widetilde{W}_{t}>\frac{1}{\sigma} \ln \frac{R}{V}} d t+\alpha s_{d} \int_{0}^{+\infty} e^{-r_{d} t} e^{\lambda \widetilde{W}_{t}} e^{-\frac{\lambda^{2}}{2} t} 1_{\widetilde{W}_{t} \leq \frac{1}{\sigma} \ln \frac{R}{V}} d t\right)$,

where $\widetilde{E}($.$) denotes the expectation operator under the new measure and \lambda=\frac{\mu}{\sigma}-\frac{\sigma}{2}$.

The resolvent operator of the Brownian motion yields (see e.g. Karatzas and Shreve, 1991, for a definition, and François and Morellec, 2008, for applications):

$$
K_{\delta}(\varphi) \triangleq \mathbb{E}\left(\int_{0}^{+\infty} e^{-\delta t} \varphi\left(W_{t}\right) d t\right)=\frac{1}{\sqrt{2 \delta}} \int_{-\infty}^{+\infty} \varphi(y) e^{-|y| \sqrt{2 \delta}} d y
$$

Which yields in our case

$$
\begin{aligned}
D_{d}(V, R, \alpha)= & s_{d} \frac{1}{\sqrt{2 r_{d}+\lambda^{2}}} \int_{\frac{1}{\sigma} \ln \frac{R}{V}}^{+\infty} e^{\lambda y} e^{-|y| \sqrt{2 r_{d}+\lambda^{2}}} d y \\
& +\alpha s_{d} \frac{1}{\sqrt{2 r_{d}+\lambda^{2}}} \int_{-\infty}^{\frac{1}{\sigma} \ln \frac{R}{V}} e^{\lambda y} e^{-|y| \sqrt{2 r_{d}+\lambda^{2}}} d y .
\end{aligned}
$$


Note that this expression depends on the sign of $\frac{1}{\sigma} \ln \frac{R}{V}$, that is, on the relative position of the state variable with respect to the renegotiation threshold. For $V>R$, we obtain

$$
\begin{aligned}
D_{d}(V, R, \alpha)= & s_{d} \frac{1}{\sqrt{2 r_{d}+\lambda^{2}}} \int_{\frac{1}{\sigma} \ln \frac{R}{V}}^{0} e^{y\left(\sqrt{2 r_{d}+\lambda^{2}}+\lambda\right)} d y+s_{d} \frac{1}{\sqrt{2 r_{d}+\lambda^{2}}} \int_{0}^{+\infty} e^{-y\left(\sqrt{2 r_{d}+\lambda^{2}}-\lambda\right)} d y \\
& +\alpha s_{d} \frac{1}{\sqrt{2 r_{d}+\lambda^{2}}} \int_{-\infty}^{\frac{1}{\sigma} \ln \frac{R}{V}} e^{y\left(\sqrt{2 r_{d}+\lambda^{2}}+\lambda\right)} d y .
\end{aligned}
$$

Which yields, after some algebra,

$$
D_{d}(V, R, \alpha)=\frac{s_{d}}{r_{d}}-\frac{(1-\alpha) s_{d}}{2 r_{d}+\lambda^{2}+\lambda \sqrt{2 r_{d}+\lambda^{2}}}\left(\frac{R}{V}\right)^{\frac{1}{\sigma}\left(\sqrt{2 r_{d}+\lambda^{2}}+\lambda\right)} .
$$

For $V \leq R$, we obtain

$$
\begin{aligned}
D_{d}(V, R, \alpha)= & s_{d} \frac{1}{\sqrt{2 r_{d}+\lambda^{2}}} \int_{\frac{1}{\sigma} \ln \frac{R}{V}}^{+\infty} e^{-y\left(\sqrt{2 r_{d}+\lambda^{2}}-\lambda\right)} d y+\alpha s_{d} \frac{1}{\sqrt{2 r_{d}+\lambda^{2}}} \int_{-\infty}^{0} e^{y\left(\sqrt{2 r_{d}+\lambda^{2}}+\lambda\right)} d y \\
& +\alpha s_{d} \frac{1}{\sqrt{2 r_{d}+\lambda^{2}}} \int_{0}^{\frac{1}{\sigma} \ln \frac{R}{V}} e^{-y\left(\sqrt{2 r_{d}+\lambda^{2}}-\lambda\right)} d y
\end{aligned}
$$

Which yields, after some algebra,

$$
D_{d}(V, R, \alpha)=\frac{\alpha s_{d}}{r_{d}}+\frac{(1-\alpha) s_{d}}{2 r_{d}+\lambda^{2}-\lambda \sqrt{2 r_{d}+\lambda^{2}}}\left(\frac{R}{V}\right)^{-\frac{1}{\sigma}\left(\sqrt{2 r_{d}+\lambda^{2}}-\lambda\right)} .
$$

Therefore, the final expression for the domestic debt value is

$$
D_{d}(V, R, \alpha)= \begin{cases}\frac{s_{d}}{r_{d}}-\frac{(1-\alpha) s_{d}}{2 r_{d}+\lambda^{2}+\lambda \sqrt{2 r_{d}+\lambda^{2}}}\left(\frac{R}{V}\right)^{\frac{1}{\sigma}\left(\sqrt{2 r_{d}+\lambda^{2}}+\lambda\right)} & \text { for } V>R \\ \frac{\alpha s_{d}}{r_{d}}+\frac{(1-\alpha) s_{d}}{2 r_{d}+\lambda^{2}-\lambda \sqrt{2 r_{d}+\lambda^{2}}}\left(\frac{R}{V}\right)^{-\frac{1}{\sigma}\left(\sqrt{2 r_{d}+\lambda^{2}}-\lambda\right)} & \text { for } V \leq R\end{cases}
$$

\section{Financial guarantee valuation}

The proof is similar to that of debt valuation. The no-arbitrage value of the financial guarantee is given by

$$
G(V, R, \alpha)=E\left(\max \left(0, \delta-s_{c}-\alpha s_{d}\right) \int_{0}^{+\infty} e^{-r_{d} t} 1_{V_{t} \leq R} d t\right),
$$

which can also be written as

$$
G(V, R, \alpha)=\widetilde{E}\left(\max \left(0, \delta-s_{c}-\alpha s_{d}\right) \int_{0}^{+\infty} e^{-r_{d} t} e^{\lambda \widetilde{W}_{t}} e^{-\frac{\lambda^{2}}{2} t} 1_{\widetilde{W}_{t} \leq \frac{1}{\sigma} \ln \frac{R}{V}} d t\right)
$$


The resolvent operator yields

$$
G(V, R, \alpha)=\max \left(0, \delta-s_{c}-\alpha s_{d}\right) \frac{1}{\sqrt{2 r_{d}+\lambda^{2}}} \int_{-\infty}^{\frac{1}{\sigma} \ln \frac{R}{V}} e^{\lambda y} e^{-|y| \sqrt{2 r_{d}+\lambda^{2}}} d y .
$$

For $V>R$, we obtain

$$
G(V, R, \alpha)=\frac{\max \left(0, \delta-s_{c}-\alpha s_{d}\right)}{\left(2 r_{d}+\lambda^{2}+\lambda \sqrt{2 r_{d}+\lambda^{2}}\right)}\left(\frac{R}{V}\right)^{\frac{1}{\sigma}\left(\sqrt{2 r_{d}+\lambda^{2}}+\lambda\right)} .
$$

For $V \leq R$, we obtain

$$
G(V, R, \alpha)=\frac{\max \left(0, \delta-s_{c}-\alpha s_{d}\right)}{r_{d}}-\frac{\max \left(0, \delta-s_{c}-\alpha s_{d}\right)}{2 r_{d}+\lambda^{2}-\lambda \sqrt{2 r_{d}+\lambda^{2}}}\left(\frac{R}{V}\right)^{-\frac{1}{\sigma}\left(\sqrt{2 r_{d}+\lambda^{2}}-\lambda\right)} .
$$




\section{Tables}

Table 1: World Bank indicators used as parameter proxies

\begin{tabular}{lcc}
\hline \hline Indicator name & World Bank code & Proxy \\
\hline Deposit interest rate & FR.INR.DPST & $r_{d}$ \\
GDP growth & NY.GDP.MKTP.KD.ZG & $\mu$ \\
Merchandise exports to high-income economies & TX.VAL.MRCH.HI.ZS & $\mu_{2}$ \\
External debt stocks (\% of GDP) & DT.DOD.DECT.GD.ZS & $s_{f}$ \\
Domestic credit provided by banking sector (\% of GDP) & FS.AST.DOMS.GD.ZS & $s_{d}$ \\
Domestic credit to private sector (\% of GDP) & FS.AST.PRVT.GD.ZS & $s_{c}$ \\
Broad money (\% of GDP) & FM.LBL.BMNY.GD.ZS & $\delta$ \\
\hline \hline
\end{tabular}

Table 1 lists the World Bank variables selected to proxy for seven model parameters. The remaining two parameters are the world interest rate $\left(r_{f}\right)$ and volatility $(\sigma)$, which will be estimated with a specific procedure. 
Table 2: Model calibration

\begin{tabular}{|c|c|c|c|c|c|c|c|}
\hline & $\begin{array}{c}\text { Sovereign } \\
\text { discount } \\
\text { rate (\%) } \\
r_{d}\end{array}$ & $\begin{array}{c}\text { Growth } \\
\text { rate }(\%) \\
\mu\end{array}$ & $\begin{array}{c}\text { Volat. } \\
(\%) \\
\sigma\end{array}$ & $\begin{array}{c}\text { Foreign } \\
\text { debt } \\
\text { service } \\
s_{f}\end{array}$ & $\begin{array}{c}\text { Domestic } \\
\text { debt } \\
\text { service } \\
s_{d}\end{array}$ & $\begin{array}{c}\text { Corporate } \\
\text { debt } \\
\text { service } \\
s_{c}\end{array}$ & $\begin{array}{c}\text { Deposit } \\
\text { flow } \\
\delta\end{array}$ \\
\hline Argentina & 1061 & 3.13 & 3019 & 6519 & 3564 & 1726 & 2672 \\
\hline Brazil & 20.78 & 2.87 & 17.56 & 29.00 & 74.90 & 37.59 & 45.69 \\
\hline Ecuador & 14.42 & 3.30 & 14.61 & 61.39 & 23.22 & 25.10 & 23.33 \\
\hline Indonesia & 14.97 & 3.96 & 27.71 & 68.42 & 50.39 & 32.34 & 44.51 \\
\hline Mexico & 9.91 & 2.28 & 9.85 & 29.81 & 37.27 & 20.27 & 27.53 \\
\hline Nigeria & 12.27 & 4.97 & 15.00 & 57.17 & 17.60 & 16.50 & 19.69 \\
\hline Philippines & 6.89 & 4.18 & 11.68 & 61.49 & 59.30 & 38.46 & 56.99 \\
\hline Romania & 24.14 & 2.97 & 16.28 & 37.05 & 24.27 & 17.92 & 28.06 \\
\hline Russia & 17.11 & 3.30 & 24.91 & 42.22 & 28.03 & 22.41 & 25.49 \\
\hline South Africa & 10.71 & 3.29 & 14.51 & 17.08 & 164.08 & 133.12 & 59.98 \\
\hline Thailand & 4.71 & 3.22 & 13.63 & 49.05 & 138.31 & 119.28 & 104.32 \\
\hline Turkey & 48.95 & 3.96 & 17.90 & 43.23 & 42.62 & 21.84 & 33.61 \\
\hline Venezuela & 18.59 & 2.87 & 17.43 & 35.29 & 17.99 & 13.88 & 20.03 \\
\hline Base case & 15 & 3 & 20 & 40 & 40 & 30 & 30 \\
\hline
\end{tabular}

Table 2 reports the average values of World Bank data over the 1995-2009 period for a selection of major participants in the sovereign debt market. Debt services and deposit flows are expressed as a percentage of GDP, which implies normalizing the state variable initial value to $V=100$. Volatility is the standard deviation of log-returns on GDP growth. The last line reports the base case selected for model simulation. The world interest rate $\left(r_{f}=0.035\right)$ is the average 3-month U.S. Treasury Bill over the 1995-2009 period. 
Table 3: Regression analysis

\begin{tabular}{|c|c|c|c|c|c|c|c|}
\hline & \multirow[b]{2}{*}{ Sign } & \multicolumn{6}{|c|}{ Specification } \\
\hline & & 1 & 2 & 3 & 4 & 5 & 6 \\
\hline Constant & & $2.501^{* * *}$ & $4.147^{\text {*** }}$ & $6.511^{\text {*** }}$ & $5.543^{* * *}$ & $5.159^{* * *}$ & $4.587^{\text {*** }}$ \\
\hline \multicolumn{8}{|c|}{ Model outputs } \\
\hline $\ln (c s)$ & + & $0.615^{* * *}$ & $0.281^{* * *}$ & & & & \\
\hline$D T D^{*}$ & - & & & $-0.052^{* * *}$ & $0.031^{* *}$ & & \\
\hline$\alpha^{*}$ & - & & & $-4.254^{* * *}$ & $-2.328^{* * *}$ & & \\
\hline \multicolumn{8}{|c|}{ Determinants } \\
\hline$r_{d}$ & + & & & & & $0.035^{* * *}$ & $0.018^{* * *}$ \\
\hline$r_{f}$ & - & & & & & $-0.113^{* * *}$ & $-0.237^{* * *}$ \\
\hline$\mu$ & - & & & & & $-3.465^{* *}$ & 1.359 \\
\hline$\sigma$ & + & & & & & $0.015^{* * *}$ & $0.013^{* * *}$ \\
\hline$s_{f}$ & + & & & & & $0.026^{* * *}$ & 0.004 \\
\hline$s_{d}$ & 0 & & & & & -0.014 & $1.962^{*}$ \\
\hline$s_{c}$ & - & & & & & 0.004 & $-0.039^{* * *}$ \\
\hline$\delta$ & + & & & & & 0.006 & -0.025 \\
\hline \multicolumn{8}{|l|}{ Time-fixed } \\
\hline effects? & & No & Yes & No & Yes & No & Yes \\
\hline \# obs. & & 169 & 169 & 169 & 169 & 169 & 169 \\
\hline Adj. $R^{2}$ & & 0.672 & 0.846 & 0.355 & 0.841 & 0.838 & 0.920 \\
\hline
\end{tabular}

Table 3 reports the regression results. The dependent variable is the natural logarithm of observed Brazilian credit spreads. Model output regressors are: the natural logarithm of modelimplied credit spreads $(\ln (c s))$, distance-to-default $\left(D T D^{*}\right)$ and recovery rate $\left(\alpha^{*}\right)$. Determinant regressors are: sovereign deposit rate $\left(r_{d}\right)$, U.S. Treasury Bill 3-month rate $\left(r_{f}\right)$, GDP growth rate $(\mu)$, estimated state variable volatility $(\sigma)$, external debt $\left(s_{f}\right)$, domestic debt $\left(s_{d}\right)$, corporate debt $\left(s_{c}\right)$, and deposits $(\delta)$. The column "Sign" indicates the positive $(+)$, negative $(-)$ or absence of (0) relation predicted by the model. Superscripts ${ }^{* * *},{ }^{* *}$, and ${ }^{*}$ indicate statistical significance at the $1 \%, 5 \%$ and $10 \%$ level, respectively. 


\section{Figures}

Figure 1: Balance-sheet model of the sovereign economy

\begin{tabular}{lll}
\hline Sector & Assets & Liabilities and net worth \\
\hline Corporate & corporate assets & $\begin{array}{l}\text { loans } \\
\text { equity }\end{array}$ \\
\hline Banking & $\begin{array}{l}\text { loans } \\
\text { domestic debt } \\
\text { financial guarantee }\end{array}$ & $\begin{array}{l}\text { deposits } \\
\text { equity }\end{array}$ \\
\hline \multirow{2}{*}{ Public } & $\begin{array}{l}\text { public assets and } \\
\text { monetary prerogative }\end{array}$ & $\begin{array}{l}\text { sovereign equity } \\
\text { domestic debt } \\
\text { external debt }\end{array}$ \\
\hline
\end{tabular}

The elements in italics are considered as fixed inputs, while the elements in bold are outputs. 
Figure 2: Balance-sheet model of the sovereign economy under contingent claims analysis

\begin{tabular}{lll}
\hline Sector & Assets & Liabilities \\
\hline \multirow{2}{*}{ Corporate } & $\frac{V}{r_{d}-\mu}$ & $D_{c}\left(V, V_{b}^{*}\right)$ \\
& $D_{c}\left(V, V_{b}^{*}\right)$ & $\left.\delta / r_{d}\right)$ \\
\hline \multirow{3}{*}{ Banking } & $D_{d}(V, R, \alpha)$ & $S_{b}(V, R, \alpha)$ \\
& $G(V, R, \alpha)$ & \\
\hline \multirow{3}{*}{ Public } & $P$ & $E(V, R, \alpha)$ \\
& & $D_{d}(V, R, \alpha)$ \\
& & $D_{f}(V, R, \alpha)$ \\
\hline
\end{tabular}




\section{Figure 3: Determinants of sovereign credit spreads: Discount rates and GDP dynamics}
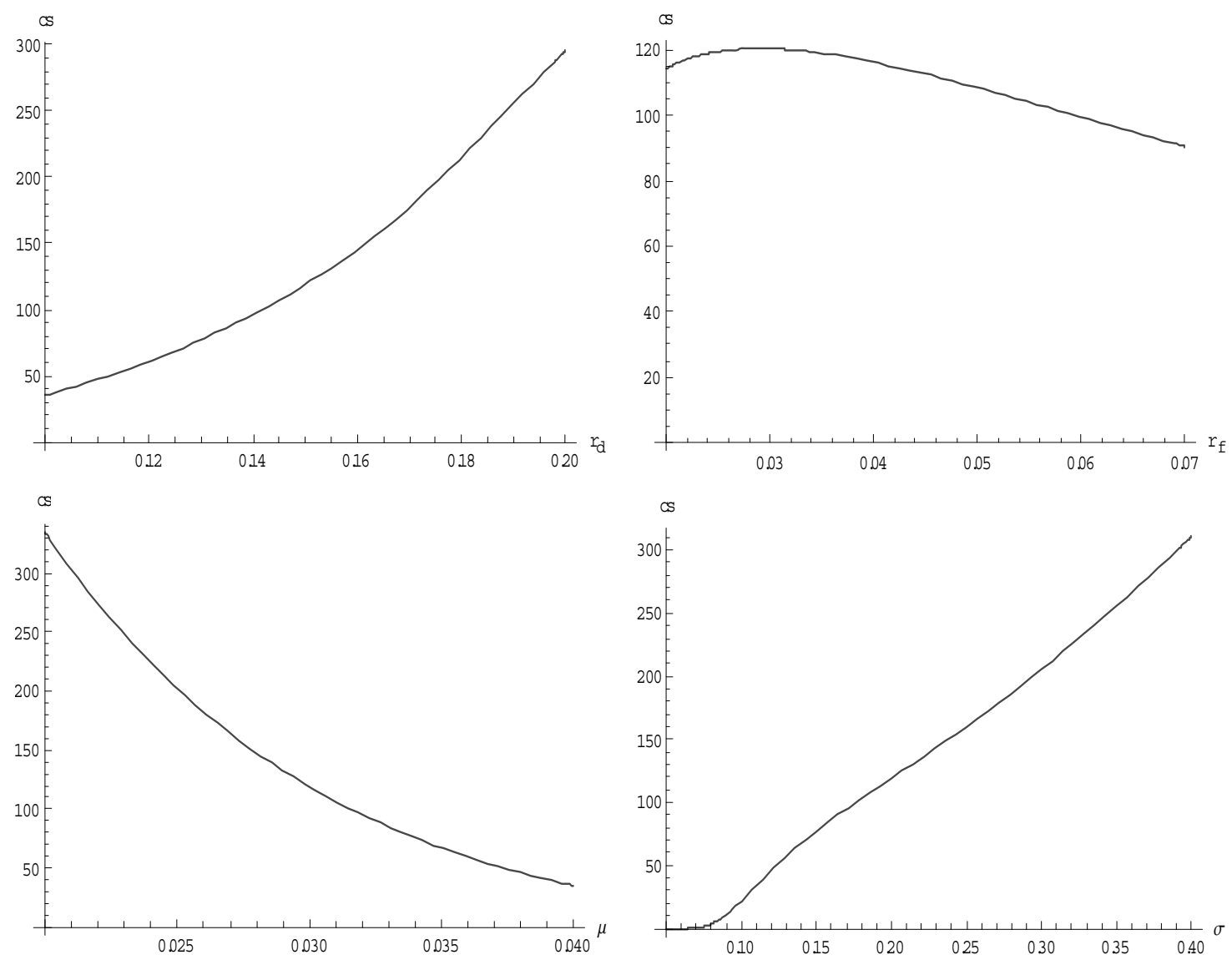

Figure 3 displays sovereign credit spreads $(c s)$ in basis points as a function of the sovereign discount rate (top left graph), world interest rate (top right graph), GDP drift (bottom left graph), and GDP volatility (bottom right graph). All other parameter values are those of the base case. 


\section{Figure 4: Determinants of sovereign credit spreads: Debt services and deposit flow}
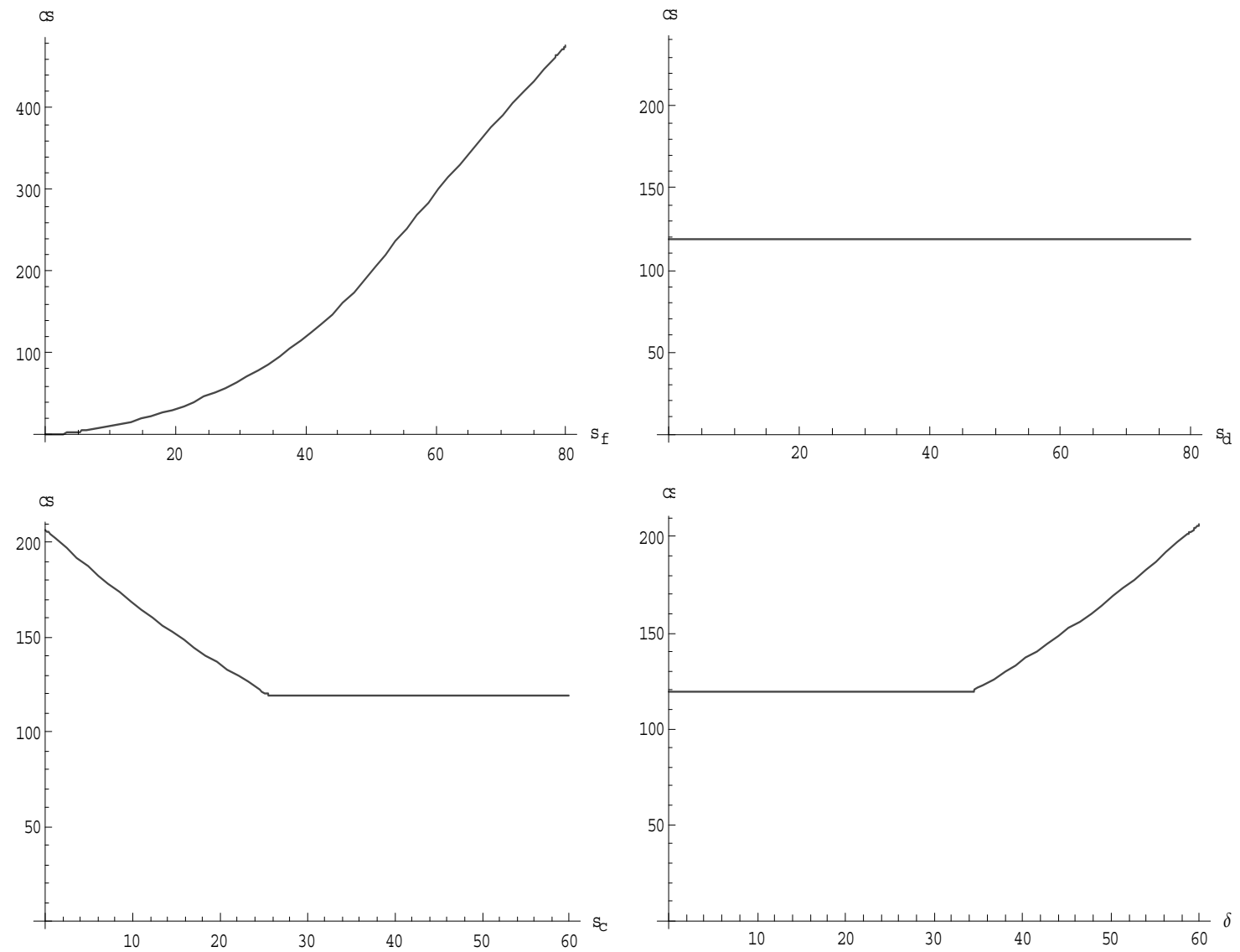

Figure 4 displays sovereign credit spreads $(c s)$ in basis points as a function of external debt flow (top-left graph), domestic debt flow (top-right graph), corporate debt flow (bottom-left graph), and deposit flow (bottom-right graph). All other parameter values are those of the base case. 


\section{Figure 5: Dynamics of model inputs for Brazil}

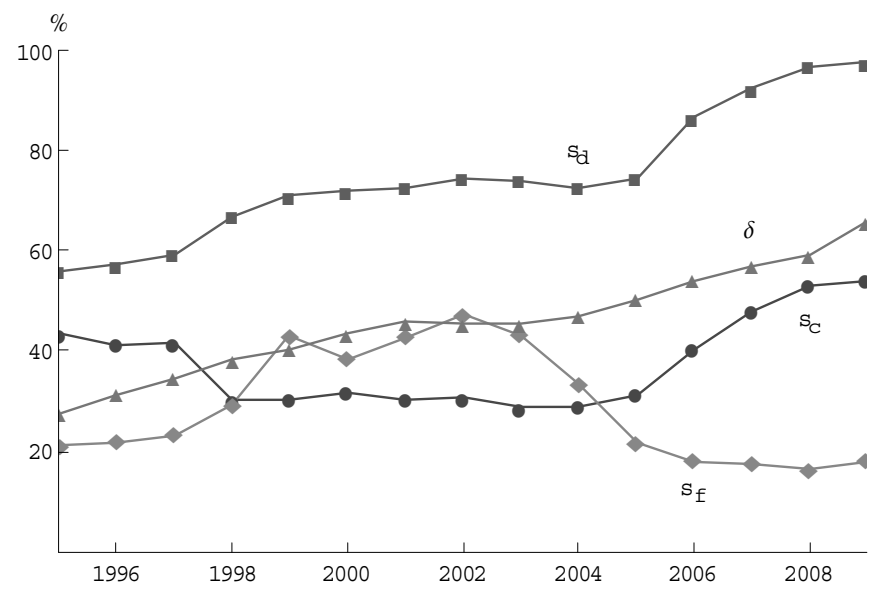

Figure 5 reports the evolution of corporate debt $\left(s_{c}\right)$, domestic debt $\left(s_{d}\right)$, foreign debt $\left(s_{f}\right)$ and deposits $(\delta)$ for Brazil. All values are expressed as a percentage of GDP. Data span the 1995-2009 period and come from the World Development Indicators (World Bank). 
Figure 6: Estimated volatility for Brazil

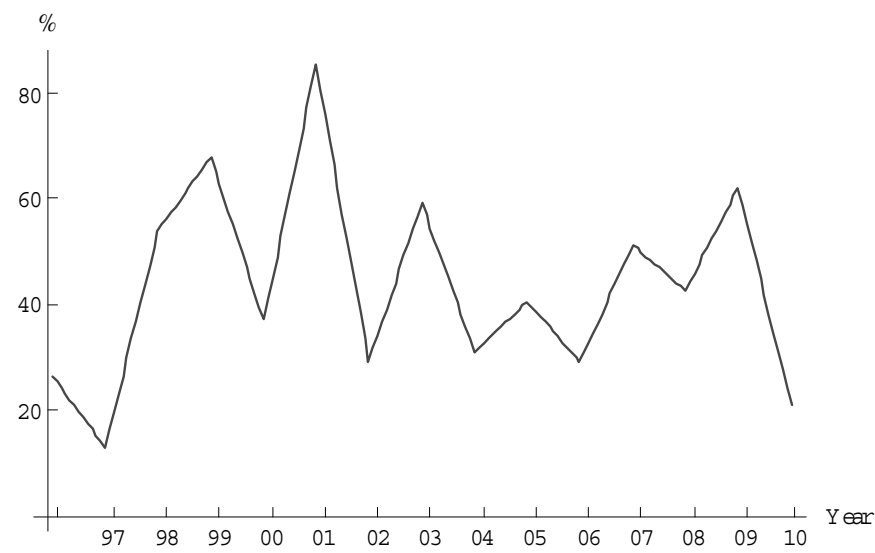

Figure 6 shows Brazil's estimated volatility from the iterative procedure. The spikes in the graph represent the volatility coefficients estimated on an annual basis (at the end of each year). Monthly estimates are then obtained from linear interpolation. 


\section{Figure 7: Model-implied and observed Brazilian credit spreads}

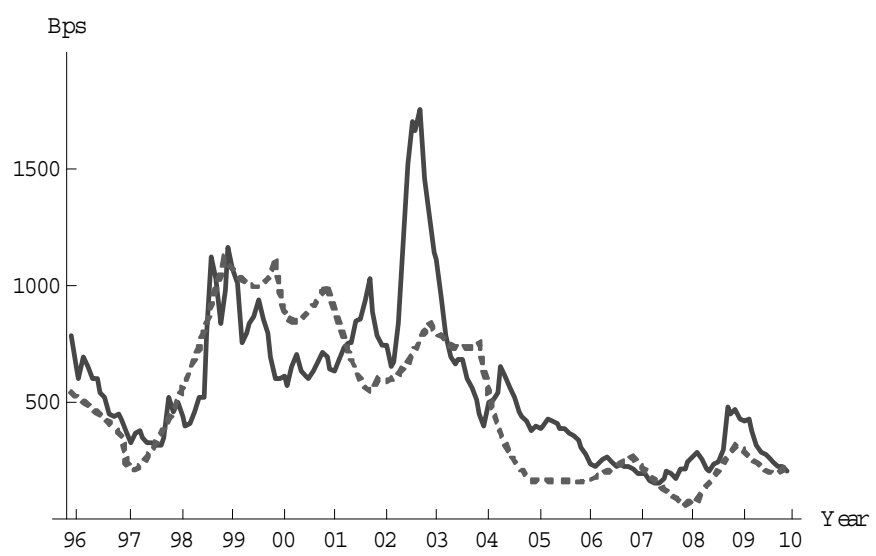

The solid line represents the JP Morgan EMBI Brazil spread. The dashed line represents the theoretical sovereign credit spreads implied by the model. 